\title{
The Effect of Parity on Health- Promoting Lifestyle Behaviors among Women in Reproductive Age at Abou-Tig district Assiut
}

\author{
Shimaa A. Ibrahim ${ }^{1}$, Rabaa H. Hassanen ${ }^{2} \&$ Asmaa K. Hassan ${ }^{3}$. \\ 1. Nursing Specialist, in Abou-Tig central hospital, Assiut City, Egypt. \\ 2. Professor of Community Health Nursing, Faculty of Nursing- Assiut University, Egypt. \\ 3. Assistant Professor of Community Health Nursing, Faculty of Nursing- Assiut University, Egypt.
}

\begin{abstract}
Health-promoting lifestyle behaviors aim to improve the individual's general health and well-being. Parity has a great effect on women's health that Women with 5+ births had a higher risk of incident health problems which in turn affect their life style. Aim: To assess the effect of parity on health-promoting lifestyle behaviors among women in reproductive age. Research design: Descriptive cross-sectional research design. Setting: The study was conducted in (1)MCH center and (4) health units at Abou-Tig district. Sample: total coverage sample (722) of married women. Two tools were used Tool 1:-Interview questionnaire sheet: include three parts(1)Socio-demographic data,(2)women's medical and obstetric history(3)knowledge about health-promoting lifestyle behaviors Tool 2: Health-Promoting lifestyle profile-II is scale assesses the individual's health-promoting attitude related to a healthy lifestyle. It included six subgroups including: health responsibility, physical activity, nutrition, interpersonal support, self-actualization, and stress management. Results: it was clear that $87.3 \%$ of women had poor knowledge about health promoting-lifestyle behaviors and $51.5 \%$ of women had satisfactory behavioral level about them. Conclusion: Most of studied women had poor knowledge about health promoting-lifestyle behaviors and half of them had satisfactory behavioral level.there is a statistically significant correlation between parity and all domains of health -promoting lifestyle behaviors Recommendations: Providing educational programs about health promoting lifestyle behaviors to increase women's knowledge and behavioral level.
\end{abstract}

\section{Keywords: Parity, Health-Promoting Lifestyle, Women \& Reproductive Age.}

\section{Introduction}

Health-promoting behaviors are one of the main determinative components of health known as an underlying factor in the prevention of many diseases. Health promotion and prevention of disease are directly associated with these behaviors, so following these health-promoting behaviors is one of the best ways by which people can protect and control their health.(Mirghafourv \& et al., 2015)

"Health promotion is the science and art of lifestyle change to reach desirable perfection. So it is receiving an ever-increasing attention regarding the prominent role it plays in the health of the population. The high costs of health services make it necessary for us to emphasis on the prevention of diseases, rather than treating the diseases(Kelly et al., 2017).

Lifestyle is defined as normal and conventional daily activities that are accepted by people during their lives and these activities can affect the health of individuals. Health requires promoting a healthy lifestyle which allows individuals to maintain and promote his/ her health and prevent diseases by having the proper diet, rest/ activity, physical exercise, controlling body weight, and stopping of smoking and immunizing the body against diseases(Tol, et al., 2013)
Health-promoting lifestyle behaviors in women who are the keystones of the family and who are the primary health care providers for the family is influenced by various factors such as health status, barriers, employment, the number and age of their children, and marital status(Sorour, et al., 2014)

Health-promoting behaviors have been identified as an effective preventative measure against health problems to improve women's health. Women in reproductive age comprise a large proportion of the population. In addition to obvious gender differences in the susceptibility to conditions related to reproductive health, comprising pregnancy and childbirth, conditions such as anemia, depression, anxiety, and eating disorders are more common in women. (Zhang et al., 2018).

Parity has a great effect on women's health that direct complications that account for more than In Egypt $70 \%$ of maternal deaths are hemorrhage, infection, unsafe abortion, eclampsia, and obstructed labor. While these are the main causes of maternal death; unavailable, inaccessible, unaffordable, or poor quality care is fundamentally responsible (El-Nagar, et al., 2017).

In developing countries, where women commonly have more than five births, high parity contributes to 
high maternal and infant mortality rates (Demissie, et al., 2015).

Nurses not only have responsibilities with the potential to influence the conditions affecting the health of others, but they also have an opportunity to be role models of good practice concerning healthpromotion(Nazik, et al., 2015).

A nurse also has a great effect on promoting the health of individuals, family, and community that health knowledge can be promoted via health education. The purpose of health education is to inform and motivate individuals to actively care for their health. Health education programs enable individuals to gain knowledge, form points of view and behavioral patterns for a healthy lifestyle (Cheng, 2015).

\section{Significance of the study}

Parity has negative effect on women's health promoting lifestyle behaviors so determining these behaviors during the important period of reproduction provides valuable information for designing appropriate intervention programs to promote women's health (Nazik, et al., 2015). Egypt realized the importance of decrease number of parity, the new birth rate decreased from to 6.68 million in 2015 to 2.55 million new births in 2017 . The governorates with the highest birth rate are Assiut, Souhag, Qena, Luxor, and Aswan so awareness campaigns for family planning programs will be held in these governorates to decrease number of parity. (CAPMAS 2018).

\section{Aim of the study}

To assess the effect of parity on health-promoting lifestyle among women in reproductive age.

\section{Research Questions}

- What is women's knowledge about healthpromoting lifestyle behaviors?

- Is there a relationship between parity and healthpromoting lifestyle among women in the reproductive age?

\section{Subjects \& Methods \\ Research Design}

The descriptive cross-sectional research design was used to achieve the aim of this study.

\section{A- Setting}

The study was conducted in Abou- Tig district at one $\mathrm{MCH}$ center and four health units were selected randomly represented as Bakoor at the North, Elnekhela at the South, Duena at the West and AbouTig city in Assiut Governorate.

\section{B-Sample}

The total sample size was 722 women, selected through purposeful sampling technique. The total number of women in reproductive age in the selected villages at Abou-Tig district is 59643. By using software EPI/Info, version 3.3with $99.9 \%$ confidence interval (CI) the estimated sample size was 657 women. To compensate for the dropout, $10 \%$ was added to the sample size.

The final sample size was 722 .

\begin{tabular}{|l|c|c|c|}
\hline Place & $\begin{array}{c}\text { Number of } \\
\text { women in } \\
\text { reproductive } \\
\text { age }\end{array}$ & $\begin{array}{c}\text { Sample } \\
\text { size }\end{array}$ & Percent \\
\hline Abu-tig city & 16158 & 238 & $33 \%$ \\
\hline Duena(W) & 14758 & 217 & $30 \%$ \\
\hline El nekhela(S) & 9645 & 144 & $20 \%$ \\
\hline Bakor(N) & 8258 & 123 & $17 \%$ \\
\hline Total & 48819 & 722 & $100 \%$ \\
\hline
\end{tabular}

Inclusion criteria

1-Married women in reproductive age (18-49)

2- Women who are free from mental illness.

\section{C-Tools of the study}

-Interview questionnaire sheet which was developed by researchers after reviewing the relevant literature it included two tools:-

Tool 1 part1: Socio-demographic data as (age, level of education, address, marital status......etc (AbdEltwaab scale 2012)

Part 2: Women history: Obstetric history as the number of gravida, parity and health problems associated with a previous pregnancy and previous delivery.

part3: Women's knowledge about health-promoting lifestyle behaviors:

as health responsibility, physical activity, nutrition, self-actualization interpersonal relationships, and stress management.

The scoring system for knowledge was as follow:

A scoring system was designed for the assessment of knowledge as the follows one grade for correct answer and zero grade for incorrect answer. The total grades are 84 . The grades of each item is summed-up and then converted into a percentage score as following: Poor knowledge $<50 \%$ ( 41 grades), Fair knowledge $=50 \%-70 \%(42$ grades -58$)$ and Good knowledge $>70 \%$ (59- 84 grades) (Khalaf, 2015)

Tool 2

Health-Promoting lifestyle profile-II [HPLP- II] was developed by Walker et al. [1987] to determine healthy lifestyle behaviors. The scale included six subgroups with a total of 48 items. The subgroups included: health responsibility, physical activity, nutrition, interpersonal support, self-actualization, and stress management. All the items of the HPLP scale are affirmative; there are no reverse questions. The answers are given within a four-point Likert-type 
scale. The answer "never" received 1 point, "sometimes" received 2 points, "frequently" received 3 , and "regularly" received 4 points. Every subgroup consisted of different items. Health responsibility included 10 items, Physical activity encompassed 5 items, Nutrition 6 items; Interpersonal support 7 items, Self-actualization 13 items and Stress management or dealing with stress 7 items. In total, the HPLP scale (min-max: 48- 192) comprised 48 items. A higher score indicated that the subject performs a higher level of the indicated behaviors. The HPLPII assesses the individual's healthpromoting behaviors related to a healthy lifestyle in which less than 50\% (96 points) is considered as poor behavioral level, satisfactory behavior $=50 \%$ 70(96_134 point) and good behavior $>70 \%$ (134points).

\section{Methodology}

\section{I-Administrative phase}

- An official letter of approval was obtained from the Dean of the Faculty of Nursing, Assiut University to the director of Directorate of Health in Assiut. This letter included a brief explanation of the objectives of the study, and asking for permission to carry out the study.

\section{II-Pilot Study}

A Pilot study included 72 women was carried out to (10\%) to ensure clarity and applicability of the developed tools, and to estimate the time required to fill the questionnaire. Based on t-96he results of the pilot study, there was no need for modifications. So women who participated in the pilot study were included in the study.

Validity of tools: The tools were reviewed to ascertain their validity by five experts in the Community Health Nursing department who reviewed the instrument for clarity, relevance, comprehensiveness, understanding, and applicability.

Reliability of tool: Was assessed using alpha Cronbach test to test the internal consistency $\mathrm{K}=0.788, \mathrm{P}=0.929$ which were accepted.

\section{II- Data collection Phase \\ Ethical consideration}

A research proposal is approved by the Ethical Committee at the Faculty of Nursing. There is no risk for studied subjects during the application of the research. The study will follow ethical principles in clinical research. Written consent will be obtained from the directors and oral informed consent will be obtained from studied women that are willing to participate in the study, after explaining the nature and purpose of the study. Confidentiality and anonymity will be assured.

\section{Field of work}

The study started on November 2017 to April 2018. The researchers introduce themselves and explain the purpose of the study for the studied women. The average time taken for completing each sheet was around 15-20 minutes depending on the persons' response to questions. The data was collected on Saturday and Sunday, in the morning. About (13-16) sheets/day.

\section{Statistical analysis}

The collected data was reviewed, prepared for computer entry, coded, analyzed and tabulated at Descriptive statistics (i.e., frequencies, percentage and mean, standard deviation, etc) 


\section{Result}

Table (1): Distribution of the studied women regarding their sociodemographic characteristics

\begin{tabular}{|c|c|c|}
\hline \multicolumn{1}{|c|}{ Variables } & No. (722) & \% \\
\hline Age: (years) & & 21.5 \\
\hline$<25$ & 155 & 26.7 \\
\hline $25-<30$ & 193 & 16.3 \\
\hline $30-<35$ & 118 & 17.9 \\
\hline $35-<40$ & 129 & 17.6 \\
\hline$\geq 40$ & 127 & \\
\hline Mean \pm SD & $\mathbf{3 1 . 0 2} \pm \mathbf{8 . 0 1}(\mathbf{1 6 . 0}-\mathbf{4 9 . 0 )}$ \\
\hline Woman's educational level & \multicolumn{2}{|c|}{} \\
\hline Illiterate & 155 & 21.5 \\
\hline Read \& write & 72 & 10.0 \\
\hline Basic education & 54 & 32.4 \\
\hline Secondary & 234 & 25.6 \\
\hline University & 185 & 3.0 \\
\hline Postgraduate & 22 & 37.5 \\
\hline Woman's occupation & & 62.5 \\
\hline Employee & 271 & 64.3 \\
\hline Housewife & 451 & 35.7 \\
\hline Residence: & & \\
\hline Rural & 464 & 22.3 \\
\hline Urban & 258 & 22.3 \\
\hline Social class: (Abd Eltwaab scale2012) & & \\
\hline Low & 162 & \\
\hline Moderate & 401 & \\
\hline High & 162 & \\
\hline
\end{tabular}

Table (2): Distribution of the studied women regarding to number of pregnancies and number of births.

\begin{tabular}{|l|c|c|}
\hline \multicolumn{1}{|c|}{ Obstetric history } & No. (722) & \% \\
\hline Number of pregnancies: & & 34.8 \\
\hline$<3$ & 251 & 36.8 \\
\hline $3-4$ & 265 & 28.4 \\
\hline More than 4 & 206 & \\
\hline Number of births: & & $\mathbf{5 . 5}$ \\
\hline None & $\mathbf{3 9}$ & $\mathbf{3 4 . 6}$ \\
\hline$>\mathbf{3}$ & $\mathbf{2 4 3}$ & $\mathbf{4 0 . 3}$ \\
\hline $\mathbf{3}-\mathbf{4}$ & $\mathbf{2 8 5}$ & $\mathbf{1 9 . 6}$ \\
\hline More than $\mathbf{4}$ & $\mathbf{1 3 9}$ & \\
\hline
\end{tabular}

16 women were primigravida 


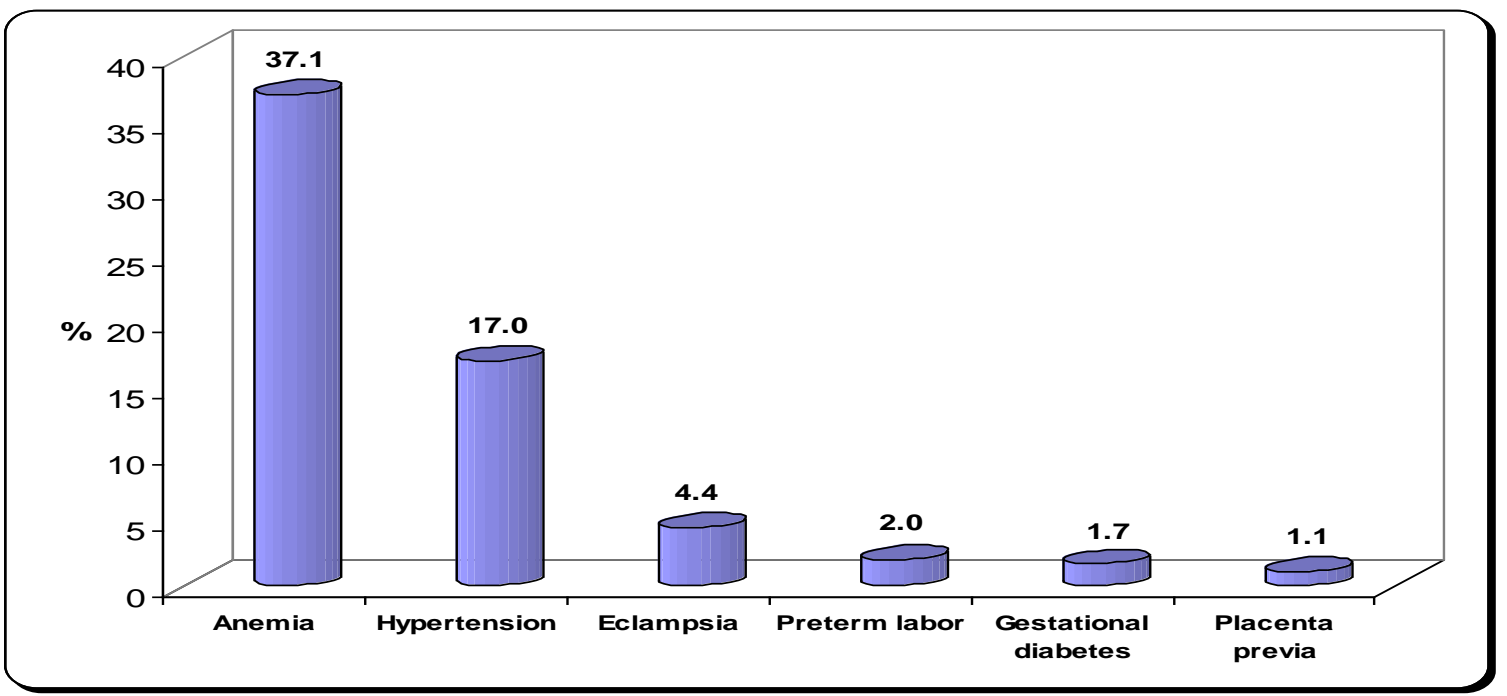

Fig (1):Health problems associated with the previous pregnancy.

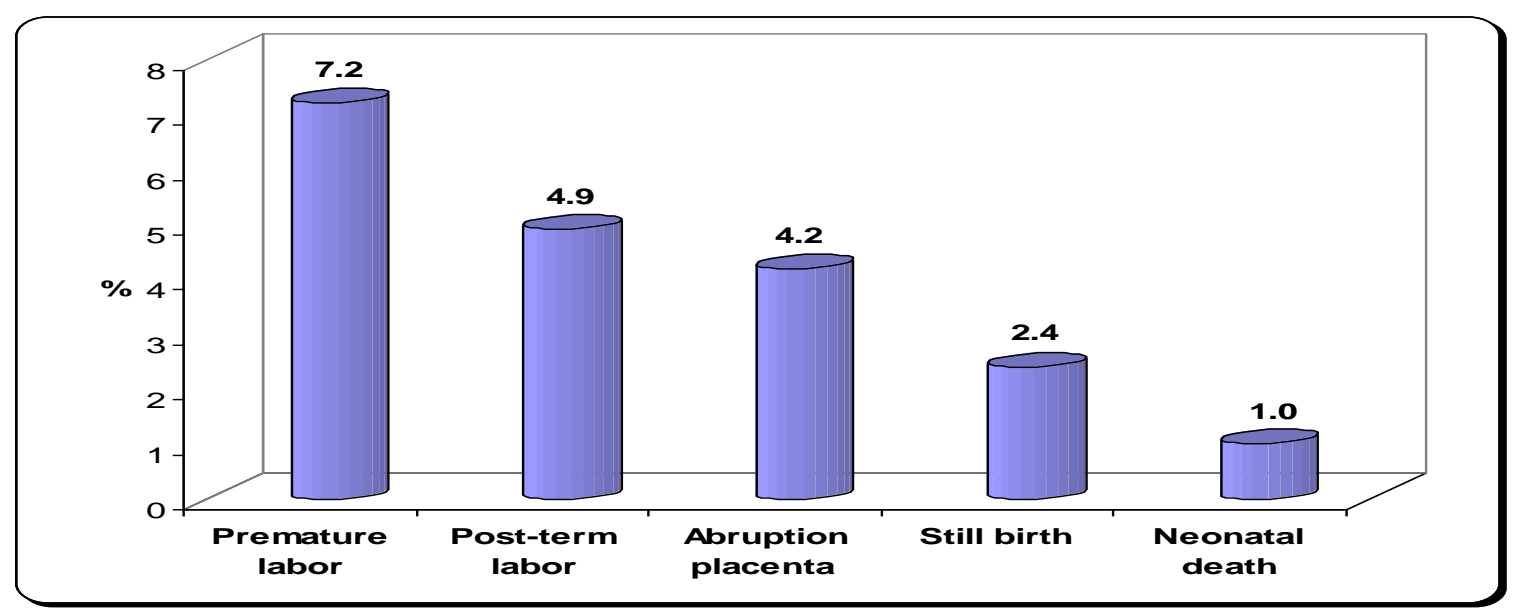

Fig (2): Health problems associated with previous delivery

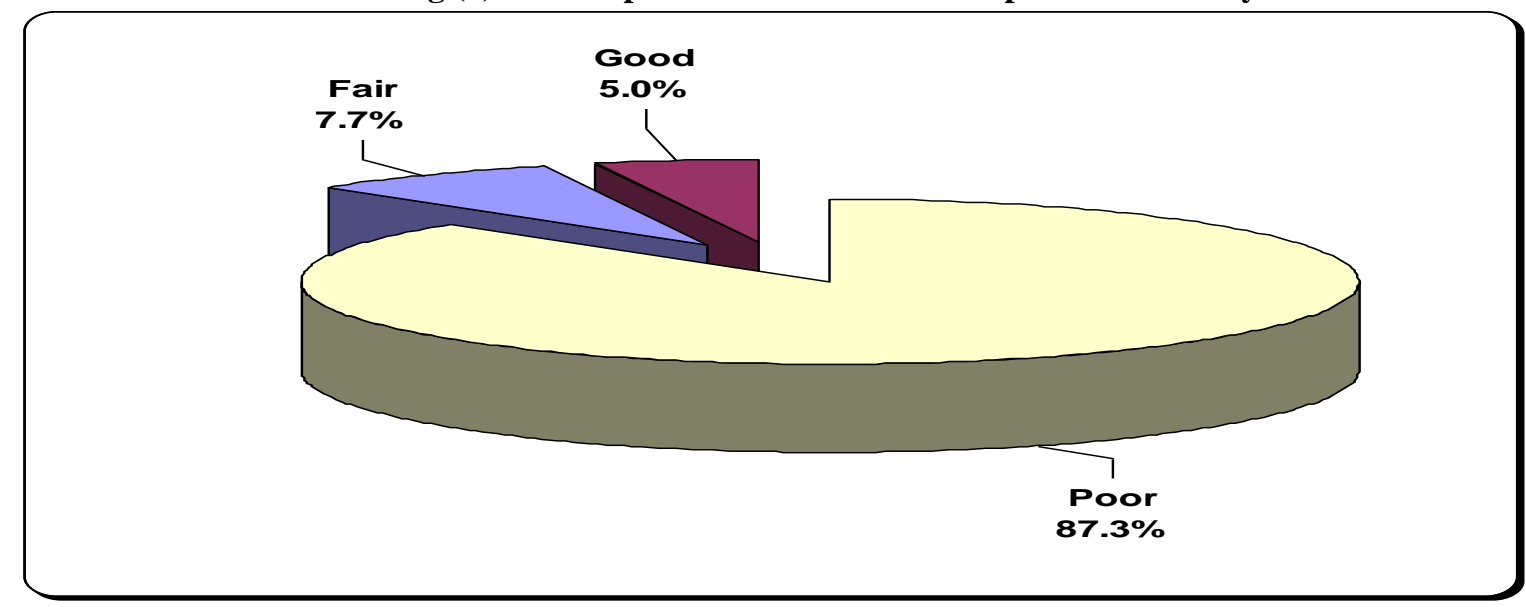

Fig (3): Total knowledge scores of studied women about health promoting lifestyle behaviors in Abou-tig city at 2018. 


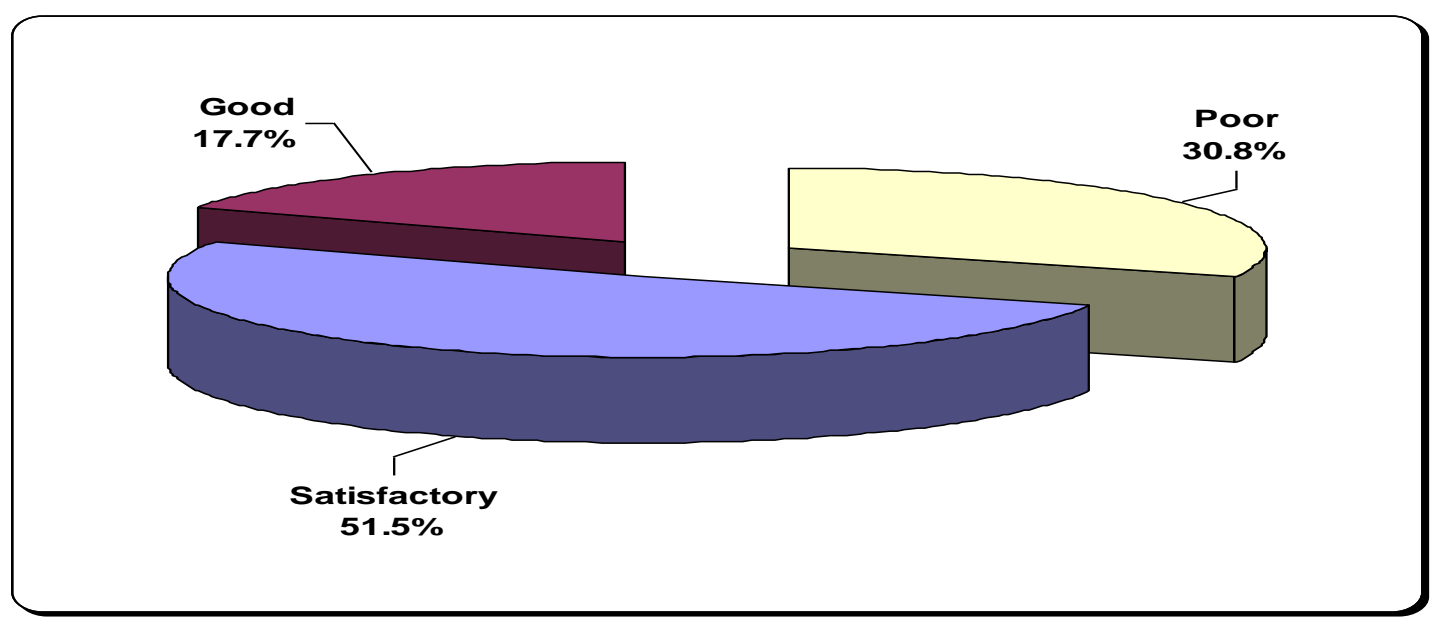

Fig.4Total behavior level of studied women regarding Health promoting lifestyle behaviors in Abou-tig city at 2018.

Table (3): Mean \pm SD of HPLP domains obtained from studied women.

\begin{tabular}{|l|c|c|c|}
\hline & Max. score & Mean \pm SD & Range \\
\hline Health & 40.0 & $18.97 \pm 6.67$ & $10.0-40.0$ \\
\hline Nutrition & 24.0 & $15.22 \pm 3.92$ & $6.0-24.0$ \\
\hline Sports & 20.0 & $9.40 \pm 3.01$ & $5.0-18.0$ \\
\hline Stress management & 28.0 & $15.55 \pm 4.92$ & $7.0-28.0$ \\
\hline Personal support & 28.0 & $18.85 \pm 5.27$ & $7.0-28.0$ \\
\hline Self-realization & 52.0 & $31.54 \pm 8.71$ & $13.0-51.0$ \\
\hline Behavior score & 192.0 & $109.53 \pm 25.40$ & $57.0-172.0$ \\
\hline
\end{tabular}

Table (4) Relations between parity and domains of health promoting lifestyle behaviors of studied women in Abou-tig city 2018.

\begin{tabular}{|l|c|c|c|c|c|}
\hline \multirow{2}{*}{} & \multicolumn{4}{|c|}{ Number of births } & \multirow{3}{*}{ P-value } \\
\cline { 2 - 6 } & None & $\mathbf{1}-\mathbf{2}$ & $\mathbf{3 - 4}$ & More than4 & \\
\cline { 2 - 6 } & Mean \pm SD & Mean \pm SD & Mean \pm SD & Mean \pm SD & \\
\hline Health & $18.15 \pm 4.77$ & $18.51 \pm 6.58$ & $19.77 \pm 6.87$ & $18.00 \pm 6.72$ & $0.033^{*}$ \\
\hline Nutrition & $15.15 \pm 3.31$ & $14.78 \pm 3.81$ & $15.79 \pm 3.96$ & $14.62 \pm 4.04$ & $0.007^{*}$ \\
\hline Sports & $8.46 \pm 2.36$ & $9.10 \pm 2.81$ & $9.88 \pm 3.15$ & $9.03 \pm 2.97$ & $0.001^{*}$ \\
\hline Stress management & $18.38 \pm 4.71$ & $16.02 \pm 4.63$ & $15.54 \pm 4.91$ & $13.56 \pm 4.69$ & $0.000^{*}$ \\
\hline Personal support & $21.46 \pm 5.32$ & $18.74 \pm 5.46$ & $18.99 \pm 5.00$ & $17.93 \pm 5.28$ & $0.003^{*}$ \\
\hline Self-realization & $33.13 \pm 7.70$ & $32.23 \pm 8.53$ & $31.97 \pm 8.49$ & $28.97 \pm 9.12$ & $0.001^{*}$ \\
\hline
\end{tabular}


Table (5): Relationship between the level of knowledge about HPLP and personal characteristics of studied women in Abou-Tig city at 2018.

\begin{tabular}{|c|c|c|c|c|c|c|c|}
\hline \multirow{3}{*}{ The Personal characteristics } & \multicolumn{6}{|c|}{$\begin{array}{c}\text { Level of knowledge } \\
\end{array}$} & \multirow{3}{*}{ P-value } \\
\hline & \multicolumn{2}{|c|}{$\operatorname{Poor}(n=630)$} & \multicolumn{2}{|c|}{ Fair $(n=56)$} & \multicolumn{2}{|c|}{$\operatorname{Good}(n=36)$} & \\
\hline & No. & $\%$ & No. & $\%$ & No. & $\%$ & \\
\hline Age: (years) & & & & & & & \multirow{6}{*}{$0.001^{*}$} \\
\hline$<25$ & 147 & 94.8 & 6 & 3.8 & 2 & 1.3 & \\
\hline $25-<30$ & 173 & 89.6 & 11 & 5.7 & 9 & 4.7 & \\
\hline $30-<35$ & 106 & 89.8 & 6 & 5.1 & 6 & 5.1 & \\
\hline $35-<40$ & 106 & 82.2 & 15 & 11.6 & 8 & 6.2 & \\
\hline$\geq 40$ & 98 & 77.2 & 18 & 14.2 & 11 & 8.7 & \\
\hline \multicolumn{7}{|l|}{ Educational level: } & \multirow{7}{*}{$0.000^{*}$} \\
\hline Illiterate & 155 & 100.0 & 0 & 0.0 & 0 & 0.0 & \\
\hline Read \& write & 60 & 83.3 & 11 & 15.3 & 1 & 1.4 & \\
\hline Basic education & 53 & 98.1 & 1 & 1.9 & 0 & 0.0 & \\
\hline Secondary & 202 & 86.3 & 19 & 8.0 & 13 & 5.5 & \\
\hline University & 141 & 76.2 & 24 & 13.0 & 20 & 10.8 & \\
\hline Postgraduate & 19 & 86.4 & 1 & 4.5 & 2 & 9.1 & \\
\hline \multicolumn{7}{|l|}{ Occupation: } & \multirow{3}{*}{$0.000^{*}$} \\
\hline Employee & 206 & 76.0 & 34 & 12.5 & 31 & 11.4 & \\
\hline Housewife & 424 & 94.0 & 22 & 4.9 & 5 & 1.1 & \\
\hline \multicolumn{7}{|l|}{ Residence: } & \multirow{3}{*}{0.330} \\
\hline Rural & 408 & 87.9 & 37 & 7.9 & 19 & 4.1 & \\
\hline Urban & 222 & 86.0 & 19 & 7.3 & 17 & 6.6 & \\
\hline \multicolumn{7}{|l|}{ Social class: } & \multirow{4}{*}{$0.000 *$} \\
\hline Low & 155 & 95.7 & 7 & 4.3 & 0 & 0.0 & \\
\hline Moderate & 354 & 87.9 & 23 & 5.7 & 21 & 5.2 & \\
\hline High & 121 & 74.7 & 26 & 16.0 & 15 & 9.3 & \\
\hline \multicolumn{7}{|l|}{ Parity: } & \multirow{5}{*}{0.155} \\
\hline None & 39 & 100.0 & 0 & 0.0 & 0 & 0.0 & \\
\hline $1-2$ & 211 & 86.8 & 20 & 8.2 & 12 & 4.9 & \\
\hline $3-4$ & 241 & 84.6 & 27 & 9.4 & 17 & 5.9 & \\
\hline 5 or more & 126 & 90.6 & 7 & 5.0 & 6 & 4.3 & \\
\hline \multicolumn{7}{|l|}{ Number of births: } & \multirow{5}{*}{0.155} \\
\hline None & 39 & 100.0 & 0 & 0.0 & 0 & 0.0 & \\
\hline $1-2$ & 211 & 86.8 & 20 & 8.2 & 12 & 4.9 & \\
\hline $3-4$ & 241 & 84.6 & 27 & 9.5 & 17 & 6.0 & \\
\hline 5 or more & 126 & 90.6 & 7 & 5.0 & 6 & 4.3 & \\
\hline
\end{tabular}


Table (6): Relationship between behaviors and personal characteristics of studied women in Abou-Tig city at 2018.

\begin{tabular}{|c|c|c|c|c|c|c|c|}
\hline \multirow{3}{*}{ The Personal characteristics } & \multicolumn{6}{|c|}{ Level of behavior } & \multirow{3}{*}{ P-value } \\
\hline & \multicolumn{2}{|c|}{$\begin{array}{c}\text { Poor } \\
(n=222)\end{array}$} & \multicolumn{2}{|c|}{$\begin{array}{c}\text { Fair } \\
(n=372)\end{array}$} & \multicolumn{2}{|c|}{$\begin{array}{c}\text { Good } \\
(n=128)\end{array}$} & \\
\hline & No. & $\%$ & No. & $\%$ & No. & $\%$ & \\
\hline Age: (years) & & & & & & & \multirow{6}{*}{$0.000 *$} \\
\hline$<25$ & 59 & 38.1 & 80 & 51.6 & 16 & 10.3 & \\
\hline $25-<30$ & 69 & 35.8 & 96 & 49.7 & 28 & 14.5 & \\
\hline $30-<35$ & 38 & 32.2 & 57 & 48.3 & 23 & 19.5 & \\
\hline $35-<40$ & 34 & 26.4 & 61 & 47.3 & 34 & 26.4 & \\
\hline$\geq 40$ & 22 & 17.3 & 78 & 61.4 & 27 & 21.3 & \\
\hline \multicolumn{7}{|l|}{ Educational level } & \multirow{7}{*}{$0.000^{*}$} \\
\hline Illiterate & 81 & 52.3 & 68 & 43.9 & 6 & 3.9 & \\
\hline Read \& write & 18 & 25.0 & 48 & 66.7 & 6 & 8.3 & \\
\hline Basic education & 20 & 37.0 & 30 & 55.6 & 4 & 7.4 & \\
\hline Secondary & 75 & 32.1 & 131 & 56.0 & 28 & 12.0 & \\
\hline University & 27 & 14.6 & 89 & 48.1 & 69 & 37.3 & \\
\hline Postgraduate & 1 & 4.5 & 6 & 27.3 & 15 & 68.2 & \\
\hline \multicolumn{7}{|l|}{ Occupation } & \multirow{5}{*}{$0.000^{*}$} \\
\hline Employee & 43 & 15.9 & 144 & 53.1 & 84 & 31.0 & \\
\hline Housewife & 179 & 39.7 & 228 & 50.6 & 44 & 9.8 & \\
\hline Working & 95 & 24.4 & 216 & 55.4 & 79 & 20.3 & \\
\hline Not working & 127 & 38.3 & 156 & 47.0 & 49 & 14.8 & \\
\hline \multicolumn{7}{|l|}{ Residence } & \multirow{3}{*}{$0.008 *$} \\
\hline Rural & 154 & 33.2 & 242 & 52.2 & 68 & 14.7 & \\
\hline Urban & 68 & 26.4 & 130 & 50.4 & 60 & 23.3 & \\
\hline \multicolumn{7}{|l|}{ Social class } & \multirow{4}{*}{$0.000 *$} \\
\hline Low & 74 & 45.7 & 78 & 48.1 & 10 & 6.2 & \\
\hline Moderate & 131 & 32.9 & 207 & 52.0 & 60 & 15.1 & \\
\hline High & 17 & 10.5 & 87 & 53.7 & 58 & 35.8 & \\
\hline \multicolumn{7}{|l|}{ Number of births } & \multirow{5}{*}{$0.032 *$} \\
\hline None & 9 & 23.1 & 23 & 59.0 & 7 & 17.9 & \\
\hline $1-2$ & 72 & 29.6 & 131 & 53.9 & 40 & 16.5 & \\
\hline $3-4$ & 78 & 27.4 & 150 & 52.6 & 57 & 20.0 & \\
\hline 5 or more & 60 & 43.2 & 60 & 43.2 & 19 & 13.7 & \\
\hline
\end{tabular}

Table (1): Shows that $26.7 \%$ of studied women were in age group from $(25-<30)$ years old with mean \pm SD $31.05 \pm 8.01$, while 21.5 of them were illiterates, $62.5 \%$ were housewives and $64.3 \%$ of them are from rural area, concerning the social class, this table found that $55.3 \%$ of the studied women are from moderate class.

Table (2): Illustrates that $36.7 \%$ of studied women were pregnant for 3 to 4 times, while $40.4 \%$ of them had about (3-4) births.

Fig (1): Shows that $37.1 \%$ of studied women were anemic, and $17 \%$ of them had hypertension during previous pregnancy.

Fig (2): Represents that $7.3 \%$ of studied women had premature delivery

Fig (3): Illustrates that $87.3 \%$ of studied women had poor knowledge scores compared to $5.0 \%$ of them had good knowledge scores

Fig (4): Shows that $51.5 \%$ of studied women had satisfactory behavioral level toward health-promoting lifestyle behaviors

Table (3): Shows HPLP domains, it was found that the highest mean score \pm SD was $31.54 \pm 8.71$ at selfrealization followed by $(18.97 \pm 6.67)$ ,(18.85 \pm 5.27$),(15.55 \pm 4.92)$ and $(15.22 \pm 3.92)$, in health responsibility, personal support, stress management and nutrition respectively while the lowest mean score was $(9.40 \pm 3.01)$ in physical activity.

Table (4): Shows relations between parity and HPLP of studied women and it was found that there was a statistical significant difference between parity and stress management, sport, self- realization, personal 
support, nutrition, and health with p-value $(0.000$, $0.001,0.001,0.003,0.007,0.033)$ respectively

Table (5): Reveals that there was a statistically significant difference between total knowledge scores and age at $\mathrm{p}=0.001$ as $94.9 \%$ of women had poor knowledge score aged $<25$. While there was a statistical significance difference between total knowledge score and educational level at $\mathrm{p}=0.001$ as $100.0 \%$ of them were illiterate and had poor knowledge scores. Also, it shows that there was a statistical significant difference between total knowledge scores and social class at $\mathrm{p}=0.001$ as 95.7\% of women in low social class had poor knowledge while there wasn't statistical significance difference between the score of knowledge and parity $\mathrm{p}=0.155$

Table (6): Illustrates that there was a highly statistical significant difference between behavior and personal characteristics with $\mathrm{p}=0.000$ also there was a highly statistically significant difference between attitude level and parity with $\mathrm{p}=0.03$ except for residence $\mathrm{p}=0.008$

\section{Discussion}

Health promotion is a broad term encompassing social, physical, mental and spiritual aspects. It refers to any kind of conscious planning and performance, which aims to improve health, prevent diseases, prevent negative consequences, increase productivity, and achieve individual and collective actualization (Ashgar, 2019)

Women, as an integral part of family and community, have a special role in providing and maintaining health and their health is considered as the underlying concept of development and socioeconomic wellbeing. They need to maintain and promote their health and well-being level to be able to perform their caring role effectively (Scheyer, (2018).

Choosing the type of lifestyle and health behaviors associated with women's health in reproductive age is not only a major role in women's health but it will have consequences that can affect the well-being of their community. (Baheiraei et al., 2013) .

This study aims to determine the effect of parity on health-promoting behaviors. The present study shows that the mean age of studied women is 30.85 .

This finding is in an agreement with (Nazik et al., 2015 \& Hajimiri, et al., 2016) who studied the effect of parity on healthy promotion lifestyle behaviors in women and the effect of parity on women's health promotion lifestyle at the first year after childbirth and found that the mean age of studied women was 33.7 and 28.8 respectively.

Concerning the educational level, this study presented that less than a quarter of the studied women were illiterate and one-third of them had a secondary level of education. This finding is in disagreement with Hamzehgardeshi et al., (2018) who studied Healthpromoting Lifestyles and Related Factors in Pregnant Women in Iran and reported that half of the studied women had high school and associate degrees and that is because this study was conducted in Iran where there are more developed rural areas than in upper Egypt.

Regarding occupation, this study stated that more than half of studied women were housewives. This was in the same line with Hamzehgardeshi et al., (2018) who reported that more than half of the studied women were housewives. This result is also supported by Joseph-Shehu \& Irinoye (2015) who studied health-promoting lifestyle practices of rural women in Southwest, Nigeria and found that more than half of studied women were housewives.

In the current study, more than one-third of studied women were anemic during pregnancy. This result is in the same line with Salem et al., (2015) who studied Epidemiology of iron-deficiency anemia among pregnant women in Menoufia Governorate, Egypt and Taiz Governorate, Yemen and found that more than one third of studied women were anemic.

The present study found that one six of the studied women had hypertension. This result agrees with Kahsay et al 2018 who found that one six of studied women had hypertension.

Regarding obstetrical history, this study reported that more than one-third of studied women were pregnant and delivered about three to four times. This finding is supported by (Rashad \& Essa 2010) who studied women's awareness of danger signs of obstetric complications in Egypt and reported that more than one -third of the studied women were pregnant two to three times and less than half of them delivered two to three times.

Regarding health-promoting lifestyle domains, the present study shows the highest mean scores are in interpersonal relations, self-actualization and nutrition. This may be related to the culture and belief of Egyptians in giving support to each other during luxury and difficult times.

The lowest mean scores were in physical activity, and stress management. This may be related to heavy duties on women that take more time, energy and rural culture that hindering them from practicing any kind of sports, take care of her health and increase stressors.

These findings are similar to Sorour et al., (2014) who studied Health- promoting lifestyle behaviors and related risk factors among female employees in Zagazig city in Egypt and illustrated that the participants got high scores on self-actualization domain nutrition and interpersonal relationship domain. 
This result also is in the same line with Yilmaz et al., (2016) who studied Health-promoting lifestyle behaviors of employees in public sector in Iran and reported that employees received the minimum point at the physical activity while the maximum point at interpersonal relations. Also, it was in the same line with Mirghafourvand et al., (2017) who studied the effect of the relationship lifestyle and the health of reproduction quality of life in women with polycystic ovarian and reported that women obtained the highest mean scores at nutrition and the lowest mean score at stress management. Another study conducted by Nazik et al., (2015) and found that the studied women got the highest mean scores at the interpersonal relationship and the lowest mean scores at physical activity.

These findings are also in an agreement with (Joseph-Shehu \&Irinoye 2015) who found that the highest mean scores were reported at selfactualization while, physical activity was observed to be the lowest. Nacar et al., (2014) who conducted a study on health promoting lifestyle behavior in medical students: a multicenter study from Turkey also agrees with the present findings and reported that the highest mean scores were at spiritual development and interaction between individuals while the lowest mean score was at physical activity

This study presented that there was a statistically significant difference between age and HPLP subscale that women of higher age groups had high knowledge about HPLP. This may be because of increased experience with age. There was also a significant difference between educational level, occupation, social class and knowledge of women about HPLP with p-value (0.001).

These findings agree with (Ahmadi \& Roosta 2015) who studied health knowledge and health-promoting lifestyle among women of childbearing age in Shiraz and reported that there was a statistically significant difference between socio-demographic characteristics and knowledge about HPLP.

It was in the same line with Gokyildiz, et al., (2014) who studied Health-promoting lifestyle behaviors in pregnant women in Turkey and reported that

a statistically significant difference between the age groups, level of education, social class and health promoting lifestyle behaviors was detected.

Abedi., et al., (2017) who studied how does healthpromoting lifestyle relate to sexual function among women of reproductive age in Iran? also agrees with these results and founded that there was a statistically significant difference between the age groups, level of education and health promoting lifestyle behavior of women.

These findings also agree with Ataei et al., (2019) who studied Study of Health Promotion Life Style
(HPLP) of Rural Primary Health-Care Workers (Behvarzes) in Khalkhal and Kosar Counties in turkey and founded that significant relationship with some of the demographic variables and health promoting lifestyle behaviors.

This study stated that there was a significant difference between parities and the six domains of health-promoting lifestyle behaviors The present results agree with Hajimiri et al., (2016) who found that there was a statistically significant difference between the number of parities and physical activity at $\mathrm{p}=0.012$, nutrition at $\mathrm{P}=0.06$ and health.

Nazik et al., (2015) agreed with this study and found that there was a statistically significant correlation between parity and health responsibility, nutrition, interpersonal support, which is the subscale of the HPLP Scale

This study disagrees with Gokyildiz, et al., (2014) who founded that there wasn't statistical significant deference between parity and health promoting lifestyle behaviors.

\section{Conclusion}

Most of the studied women had poor knowledge about health promoting lifestyle behaviors while half of them had satisfactory behavioral level toward it. Parity had no effect on women's knowledge about health promoting lifestyle behaviors, while there was a statistically significant difference between parity and women's behaviors toward health promoting lifestyle behaviors.

\section{Recommendations}

1- Health education programs about health promoting lifestyle behaviors and needs for reproductive period should be given for women at $\mathrm{MCH}$ centers and health units to help them to improve their health.

2- Health education for women through mass media such as, TV and Radio about health promoting lifestyle behaviors

3- Provide further research about healthy lifestyle and how to improve women health

\section{References}

1. Ahmadi, A., \& Roosta, F., (2015): Health Knowledge and Health Promoting Lifestyle Among Women of Childbearing age in Shiraz. Women's Health Bull, 2(3), 27-30.

2. Abd El-tawab A., (2012): socioeconomic scale,faculty of education

3. Ashgar, R., (2019): Personal Satisfaction, Cardiovascular Disease Risk, And Health Promoting Behavior Among Arab American Middle-Aged WomenWayne State University Dissertations. 2142. 
https://digitalcommons.wayne.edu/oa_dissertati ons $/ 2142$.

4. Ataei, J., Kamran, A., Shekarchi, A., Etebar, I., Haghiri, E., \& Gorbani, M., (2019): Study of Health Promotion Life Style (HPLP) of Rural Primary Health-Care Workers (Behvarzes) in Khalkhal and Kosar Counties, 1395. Journal of Health, 9(5), 530-540.

5. Baheiraei, A., Mirghafourvand, M., Mohammadi, E., Nedjat, S., (2013): Healthpromoting behaviors and social support in Iranian women of reproductive age, Int $\mathrm{J}$ Public Health,

https://www.researchgate.net/publication/256664 980

6. Capmas (2018): (Egypt's Statistics Body Central Agency for Public Mobilization and Statistics) www.capmas.gov.eg

7. Cheng, Y., (2015): Investigation and countermeasures on the health-promoting lifestyle of the disabled elderly in a rural area. Chinese Nursing Research, 2(4), 107-109.

8. Demissie, E., Dessie, F., Michael, F., \& Tadele, N., (2015). Level of Awareness on Danger Signs of Pregnancy among Pregnant Women Attending Antenatal Care in Mizan Aman General Hospital , Southwest, Journal of Women's Health Care. Journal of Women's Health Care, 4(8), 8-11.

9. El-Nagar, A., Ahmed, M., Belal, G., (2017).Knowledge and Practices of Pregnant Women Regarding Danger Signs of Obstetric Complications, Journal of Nursing a nd Health Science, 6 (1), 30-41

10. Gokyildiz, S., Alan, S., Elmas, E., Bostanci, A., \& Kucuk, E., (2014). Health-promoting lifestyle behaviours in pregnant women in $\mathrm{T}$ urkey. International journal of nursing practice, 20(4), 390-397.

11. Hajimiri, K., Shakibazadeh, E., Asghar, A., \& Mehrizi, H., (2016): Effect of Parity on Women 's Health Promotion Lifestyle at the First Year after Childbirth. Health Education and Health Promotion, 4(4).

12. Hamzehgardeshi, Z., Keshvar, S., \& Soraky, M., (2018): Health-promoting Lifestyles and Related Factors in Pregnant Women. Internal Medicine and Medical Investigation Journal, 3(4), 12-17.

13. Joseph-ShehuE M., Irinoye O., (2015): Health Promoting Lifestyle Practices of Rural Women in OSUN State, Southwest, NigeriaIOSR Journal of Nursing and Health Science (IOSR-JNHS) eISSN: 2320-1959.p- ISSN: 2320-1940 Volume 4, Issue 3 Ver. IV (May. - Jun. 2015), PP 08-17

14. Kahsay, H., Gashe, F., \& Ayele, W., (2018): Risk factors for hypertensive disorders of pregnancy among mothers in Tigray region, Ethiopia: matched case-control study. BMC pregnancy and childbirth, 18(1), 482.

15. Kelly M., Wills J., \& Sykes S., (2017): Do nurses' personal health behaviours impact on their health promotion practice? A systematicreview. Int J Nurs Stud 2017; 76: 6277.

16. Khalaf, F., (2015): Screening of Assuit Employees for Glaucoma as a Basis for Educational Program Thesis As a part of fulfillment for Doctoral Degree in Community Health Nursing, Pp48.

17. Mirghafourvand, M., Sakineh MohammadAlizadeh Charandabi2, T., (2017): Effect Relationship Lifestyle and on the Health of Reproduction Quality of Life in Women With Polycystic Ovarian. International Journal of Women's Health and Reproduction Sciences, 5(4), 318-323.

18. Nacar, M., Baykan, Z., Cetinkaya, F., Arslantas, D., Ozer, A., Coskun, O., Yilmaze, G., (2014): Health Promoting Lifestyle Behaviour in Medical Students : a Multicentre Study from Turkey. Asian Pacific Journal of Cancer Prevention, 15(20), 8969-8974.

19. Nazik, H., Nazik, E., Özdemir, F., Gül, Ş., \& Tezel, A., (2015): Effect of parity on healthy promotion lifestyle behavior in women. Contemporary Nurse: A Journal for the Australian Nursing Profession.

20. Rashad, W., \& Essa, R., (2010): Women's Awareness of Danger Signs of Obstetrics Complications. Journal of American Science, 6(10), 1299-1306.

21. Salem, M., Mahrous, O., El Shazly, H., Ibrahem, R., \& Al-oshari, S., (2016): Epidemiology of iron-deficiency anemia among pregnant women in menoufia governorate, Egypt and Taiz Governorate, Yemen: Acomparative study. Menoufia Medical Journal, 29(4), 1005.

22. Scheyer, K., (2018): The Effects of Demographic and Socioeconomic Factors on LifestyleBehaviors in Mothers (Doctoral dissertation, University of Colorado at Denver)ProQuest., .

23. Sorour, A., Kamel, W., Mohammed, E., Aziz, A., \& Aboelseoud, A., (2014): Health promoting lifestyle behaviors and related risk factors among female employees in Zagazig city. Journal of Nursing Education and Practice, 4(5).

24. Tol, A., Tavassoli, E., Shariferad, G., \& Shojaeezadeh, D., (2013): Health-promoting lifestyle and quality of life among undergraduate students at school of health, Isfahan University of medical sciences. Journal of Education and 
Health Promotion, 2, 29-32.

25. Yilmaz, A., Demir, G., \& Esenturk, O., (2016): Health-promoting lifestyle behaviors of employees in public sector. Science, Movement and Health, 16(2), 285-292.

26. Zhang, C., Zhu, R., Lu, J., Xue, Y., Hou, L., L., M., \& Zheng, X., (2018). Health promoting lifestyles and influencing factors among empty nesters and non-empty nesters in Taiyuan, China: a cross-sectional study. Health and Quality of Life Outcomes, 16(103), 1-8. 